\title{
Supervivencia en cáncer de pulmón localmente avanzado y metastásico estadios IIIB y IV
}

\section{Pedro Luis Ramos Guette, María Athenas Ramos, Diana Silva}

Correo electrónico: pramos152@yahoo.com

Introducción: el cáncer de pulmón es la primera causa de incidencia y mortalidad en el mundo. El propósito de este estudio es evaluar la supervivencia global y libre de progresión en pacientes con cáncer de pulmón en estadios avanzado y metastásico.

Métodos: se trata de un estudio analítico tipo cohorte, retrospectivo, realizado durante el período del $1^{\circ}$ de enero de 2005 hasta el 30 de julio de 2016. Se construyeron curvas de supervivencia con el método de Kaplan-Meier, se compararon con el método de rangos logarítmicos y se efectuó un análisis de regresión de rangos proporcionales por Cox.

Resultados: se identificó un total de 190 pacientes, con una edad promedio de 64,7 años, el 90,5\% estaba en estadio IV metastásico y el $51 \%$ era de sexo masculino. La mayoría de los pacientes tenía adenocarcinoma (62,6\%); además, el 11,58\% era EGFR positivo. La sobrevida global media está en 18,9 meses y el EGFR mutado tiene una tendencia a mejorar la supervivencia global HR 0,71 (IC95\% 0,31-1,58; $p=0,40$ ), pero no es significativa. El ECOG $0-1$ se asocia con mejor supervivencia global HR 0,49 (IC95\% 0,33-0,73; $p=0,001)$. La supervivencia libre de progresión tiene una mediana de 11,6 meses. El ECOG 0-1 se relaciona con una mejoría en la supervivencia libre de progresión HR 0,47 (IC95\% 0,32-0,68; $p=0,00$ ) y el EGFR mutado tiene HR de 0,74 , pero no es significativo.

Conclusión: los pacientes con cáncer de pulmón avanzado tienen una mejor supervivencia si poseen un buen estado funcional; en cambio, esta se ve disminuida si presentan estadio IV metastásico.

\section{Implementación de un programa de remisión libre de tratamiento (RMT) en pacientes con leucemia mieloide crónica (LMC) en un hospital universitario de Bogotá}

\author{
- Virginia Abello, María Helena Solano, Claudia Patricia Casas, Daniel Espinosa, Bonell Patiño, María Isabel Arbeláez
}

Correo electrónico: virginia.abello@gmail.com

Introducción: los inhibidores de tirosina quinasa (ITK) cambiaron la historia de la LMC, convirtiéndose en la terapia estándar debido a su alta efectividad y a su buen perfil de seguridad. Sin embargo, el tener que recibir en forma indefinida estos medicamentos se relaciona con efectos adversos que no son despreciables, alteraciones en la calidad de vida y costos significativos a los sistemas de salud. Múltiples estudios han demostrado que, con el uso prolongado, algunos sujetos seleccionados alcanzan niveles de profundidad de respuesta que permiten suspender en forma indefinida el tratamiento, sin riesgo de progresión a fase acelerada o crisis blástica. El diseño de un programa de RLT estandarizado y bien vigilado es indispensable para intentar esta estrategia.

Métodos: todos los pacientes con LMC tratados en el Hospital de San José fueron evaluados para los criterios de descontinuación. Quienes los cumplieron fueron presentados en Junta de Decisiones, firmaron un consentimiento informado y fueron incluidos en un programa formal de RLT. Se realiza seguimiento telefónico semanal durante el primer mes y control clínico mensual, con PCR 4,5, para detectar recaída molecular tempranamente. Se describen los resultados de los tres pacientes descontinuados hasta la fecha.

Resultados: de una cohorte de 74 pacientes en tratamiento activo en la institución, 15 cumplen con los criterios para descontinuación; a la fecha 3 pacientes lo han descontinuado. Los tres pacientes debutaron en fase crónica y no requirieron nunca una segunda línea; en promedio recibieron 9,3 años de ITK y estuvieron en RMM 7 años, antes de intentar RLT. En una paciente se inició la descontinuación después de un derrame pleural grado 3-4 secundario a dasatinib persistente. El tiempo en RLT es de 24, 5 y 5 meses, hasta la fecha de este reporte. La paciente de mayor tiempo en RLT presentó un síndrome de retirada de ITK, caracterizado por fascitis palmar bilateral severa, que requirió manejo con esteroides y se resolvió completamente a los tres meses de tratamiento. Los tres pacientes permanecen en RM 4,5 indetectable.

Conclusiones: la RLT es un objetivo real para un grupo seleccionado de pacientes con LMC tratados con ITK. La implementación de programas bien controlados de RLT puede permitir ofrecer esta alternativa a algunos pacientes en nuestro medio en forma segura. 